\title{
How Can China Resolve the NIMBY Dilemma in a Network Society? Government and Society-Negotiated Decisions Based on Evolutionary Game Analysis
}

\author{
Cui Tian ${ }^{1, *}$ and Chuanfeng Han ${ }^{2}$ \\ 1 School of Economics and Management, Shanghai University of Electric Power, Shanghai 200090, China \\ 2 School of Economics and Management, Tongji University, Shanghai 200092, China; hancf@tongji.edu.cn \\ * Correspondence: cuitian@shiep.edu.cn
}

check for updates

Citation: Tian, C.; Han, C. How Can China Resolve the NIMBY Dilemma in a Network Society? Government and Society-Negotiated Decisions Based on Evolutionary Game Analysis. Sustainability 2022, 14, 1308. https://doi.org/10.3390/su14031308 Academic Editor: Maria Rosa Trovato Received: 14 December 2021 Accepted: 20 January 2022 Published: 24 January 2022

Publisher's Note: MDPI stays neutral with regard to jurisdictional claims in published maps and institutional affiliations.

Copyright: (c) 2022 by the authors Licensee MDPI, Basel, Switzerland. This article is an open access article distributed under the terms and conditions of the Creative Commons Attribution (CC BY) license (https:/ / creativecommons.org/licenses/by/ $4.0 /)$.

\begin{abstract}
Infrastructure, such as waste incineration infrastructure, is entangled in the "not in my back yard" (NIMBY) dilemma. Consequently, the closed public decision-making model has difficulty adapting to the increasingly strong public-participation needs. Thus, a new mode of negotiated decision making is urgently required. This paper focuses on the negotiation problem, considers the government and society as game players, builds an evolutionary game model of negotiated decisions based on the bounded rationality hypothesis, and simulates the process and results of the evolution of the players' strategy. The study concludes that the stable state of system evolution depends on the initial state of the dual populations and the comparative relationship between changes in revenue and cost, and the sufficient and unnecessary condition for the government and society to both agree on the given strategy. Taking the waste incineration projects in Yuhang and Chaonan as examples, the negotiated decision-making practice of NIMBY facilities is analysed, and it is found that it takes less time for the system to reach equilibrium in the latter. Finally, optimisation strategies for decision making regarding NIMBY facilities are systematically proposed.
\end{abstract}

Keywords: NIMBY facilities; network society; social participation; negotiated decision making; evolutionary game

\section{Introduction}

The widespread application of modern information technology and the comprehensive penetration of the internet have pushed human society into a "network society" [1-3]. The network society is a globally networked social structure operated by information and communication technologies across microelectronics and digital computer networks [4]. However, the network society is not a cyber society, but rather a complex society formed by the interaction and integration of the real society and its mapping in internet space (which is the virtual society) [5]. The interaction between real and virtual society has allowed social activities to become free of constraints related to time and space and has weakened the government's information control and resource-allocation rights [6].

With increasing industrialisation, urbanisation and modernisation in China, the demand for infrastructure has increased dramatically. However, some infrastructures have negative externalities, such as petroleum refining facilities, thermal power stations, waste incineration plants, and magnetic levitation. Against the background of rising environmental, subject and rights awareness of the public, as well as more convenient channels of communication, it is unsurprising to witness resistance and opposition among people around these facilities, exemplifying the so-called "not in my backyard" (NIMBY) effect [7-10]. Such facilities with negative externalities can be called NIMBY facilities. For example, mass demonstrations against P-Xylene(PX) projects have occurred in Xiamen, Dalian, Ningbo, Kunming and Maoming, and several mass demonstrations against garbage incineration projects have occurred in Beijing, Panyu and Yuhang. The NIMBY facilities' environmental 
risks have been magnified and stigmatised, and they have encountered the problem of "project-protest-discontinuation", henceforth abbreviated as the NIMBY dilemma.

Some scholars have analysed the causes of NIMBY conflicts from the angles of politics, economics and social psychology [11-14]. Existing studies focus primarily on the formation mechanism [15] and evolutionary logic of NIMBY conflicts [16] using diachronic analysis, survey study methods or examining the psychology and behaviour of local governments and affected people in decision making in NIMBY projects using specific cases. Governance strategies for NIMBY conflicts have been proposed based on technological improvement, benefit compensation and citizen participation $[17,18]$, but most of them focus on end treatment, and there is little analysis of the NIMBY dilemma from the perspective of public policy.

The NIMBY dilemma originates in the government's monopoly of decision-making power and agenda setting under traditional management philosophy [19]. The government's adoption of the closed decision-making model of "decision-announcement-defence", which lacks substantive public participation [20], leads to an imbalance between government supply and public demand [21] and uncoordinated interests among the government, the market, and society. This situation results in public resistance, which ultimately leads to the failure of decision-making. Change to the decision-making model to overcome the NIMBY dilemma and meeting the needs of economic and social growth is an urgent issue.

Since NIMBY facilities are related to the vital interests of the people and overall economic and social development, public participation in decision making is required. To make public decision making more scientific and democratic, local governments have begun to reform the public decision-making process. Concomitantly, methods and channels for social participation have been innovated in the network society, and the public's subjective role and discourse power have been highlighted and enhanced, affecting the construction of public policy issues and even planning choices, so that the public decision-making mode of social participation negotiation can be realised.

Therefore, decisions on NIMBY facilities must be based on subjective democratic methods and objective scientific means [22]. The decision-making process must be opened up further with the "participation-negotiation-consensus" model to incorporate the heterogeneous demands, opinions and suggestions of stakeholders, and achieve the unity of value judgement and factual judgement by full communication and negotiation [23]. This approach will help reach consensus on project construction and the operation management mode and benefit sharing method so that decisions can be smoothly implemented with public approval.

Existing research suggests that public participation and multisubject negotiation may create noise and interference [24], increase decision complexity, reduce decision-making efficiency [25], and continue opposition and stalemates [26]. How then can multiple subjects negotiate to achieve a balanced distribution of benefits and recognition of decision-making results while ensuring decision-making efficiency?

Negotiated decision making is a game in which the government and participants repeatedly communicate and negotiate. Traditional game theory takes complete rationality as the hypothesis, which requires information to be true and complete and the game subject to have perfect judgement capabilities. However, these conditions are actually difficult to meet. In reality, most decision makers are bounded rational and cannot make completely rational judgements and choices [27]. Due to the complexity of problems, the long-term nature of the process, and information incompleteness and asymmetry, all players are bounded rational. It is difficult to devise the optimal strategy. Instead, better decisions are sought through dynamic processes such as imitation, learning and mutation in multiple games, and successful strategies spread and tend to be stable among the participating groups [28]. Using evolutionary game theory based on bounded rationality, the alternation of subjects' behaviours can be abstracted into a gradual evolutionary process of adaptive adjustment of the subject with learning ability.

Smith and Price [29] integrated biological evolution theory and classical game theory and proposed an evolutionary stability strategy based on ecological evolution. Taylor 
and Jonker [30] elaborated a replicator dynamics equation to describe the evolution of the frequencies of population types, taking into account their mutual influence on their fitness. An evolutionary game analysis is helpful to understand the emergence, transformation and stability of cluster behaviours [31,32], and has become an effective tool for examining interaction behaviours between subjects. Many scholars have applied it to research on the gaming relationship among various subjects in the field of public management [33]. For example, Xia and Luo [34] studied the strategies of the government and residents during the construction of NIMBY facilities, Yan et al. [35] analysed the strategic evolution of the public and investment companies in the planning of NIMBY facilities, and Qian et al. [36] examined the environmental compensation issues of NIMBY facilities.

Therefore, this paper will construct an evolutionary game model of government and social subject negotiation in decision-making. The equilibrium points of the evolutionary process will be identified based on the replicator dynamics mechanism, the stability of which will be analysed. The evolutionary process and results of game players' strategies will be studied through simulation, and the main influencing factors of the evolutionary game equilibrium will be identified. Taking two typical waste incineration projects as examples, the decision-making dilemma and the breakthrough of China's NIMBY facilities will be scrutinized. Finally, several decision-making optimisation strategies will be proposed.

\section{Multi-Interest Appeals in Public Decision Making}

Decision making for NIMBY facility projects involves stakeholders such as the government, enterprises, the public, social organisations and the media. There are different interests between subjects, and they work together in the decision-making process.

As representatives of the public interest, the government should express and realise the public's interests. However, as a group of people, decision-making institutions inevitably have their own interests or departmental interests and do not necessarily represent the public's interests. Moreover, the scopes, periods and priorities considered by the central and local governments and different local governments are distinct. Market-oriented reform has increased the government's profit-seeking tendency. Different levels of governments in the vertical and functional departments at the horizontal level compete with each other [37], resulting in the fragmentation of public space, public interest departmentalisation and localisation [38].

As profit-oriented economic entities, enterprises are driven by profit maximisation, and there may be contradictions between profit-seeking behaviour and public interest. In the process of public decision-making, enterprises may rely on economic power to create false "public appeals" by manipulating public opinion to influence public decision making to realise their interests, causing public policies to deviate from the public interest.

The public is paying increasing attention to individual economic interests, and the diversification and differentiation characteristics of social interest appeals are obvious. Thus, it is easy to move towards collective egoism. There is a tension between the public's cognition of the public production mode and the government's viewpoint, which may conflict with the government's long-term general interests. For example, the public opposes projects related to the national economy and people's livelihoods, such as waste incineration projects, due to concerns about the depreciation of real estate and environmental pollution.

Social organisations, as groups formed by people to achieve specific goals, represent group interests. In the process of public decision-making, social organisations choose the same strategy as the public. For example, in the mass demonstration of the Kunming p-Xylene project, environmental protection social organisations such as "Green Watershed" and "Green Kunming" jointly opposed the project's site selection with the public.

To improve communication, credibility and influence, the media (especially new media) have begun to change role cognition and functional orientation and pay more attention to the needs and acceptance of the audience. The media have become important platforms for reflecting social reality, expressing public demands, and communicating between the government and the public and thus have opened an important window 
for enhancing the transparency of decision-making, thereby affecting the efficiency and recognition of public decision-making.

The value preferences and interest appeal of the government, enterprises, the public, social organisations and the media are different. Public decision making is essentially a dynamic process in which multiple factors interact and multiple subjects play games, negotiate repeatedly, and seek a balance of interests. In the context of the network society, the dynamics, relevance, and extensive influence of public decision making increases the complexity of decision making and determines that the decision-making body must become the public subject. In the processes of decision making, agenda construction, policy design and selection, stakeholders negotiate to maintain and realise their interests. Due to the characteristics of both historical and strategic uncertainty, public decision making should be led by the government. Social subjects such as enterprises, the public, social organisations and the media pay more attention to short-term interests or certain interests, and there are contradictions and conflicts between these different interests.

Only the government can broadly consider the overall interests of society and the longterm effectiveness of policies, grasp and address the strategic and complex issues of public decision-making, and authoritatively distribute social value. Therefore, the government should lead the public decision-making process, adopt various approaches to dynamic negotiation among multiple subjects, realise the comprehensive coordination and balanced allocation of social interests, and ensure the scientific soundness and acceptability of public policies.

\section{Evolutionary Game Model of Negotiation and Decision Making between the Government and Society}

\subsection{Evolutionary Game Model}

Generally, in public decision-making, the government or its authorised implementing agencies construct decision-making issues and select thinktanks or enterprises through public bidding to design decision-making plans using professional technology and scientific methods or thinktanks, enterprises, and experts propose public decision-making issues and policy plans to the government. Then, government decision-making departments publicise decision-making plans and organise social subjects to participate in optimal plan selection through public opinion surveys, online voting, forums, hearings, or discussion meetings.

According to the basic principle of evolutionary game theory, public decision-making needs to consider the two following kinds of game players: the government and society. Both the government and society are relatively generalised concepts. The former refers to decision-making leaders such as the government and functional departments, including enterprises responsible for decision-making design and implementation, while the latter refers to decision-making participants such as the public and social organisations (the media do not directly participate in negotiation and decision making but influence decisionmaking subjects' behaviour through information reports). In the process of public decision making, different social subjects are in the same position, and the form of their income function is the same. Therefore, society can be used to refer to decision-making participants. Affected by information asymmetry and other uncertain factors, both groups are bounded rational and might not make optimal decisions. For public decision-making programmes, society's strategy set is (Agree, Oppose), abbreviated as $(p, \bar{p})$, and the government's strategy set is (Agree, Oppose), abbreviated as $(g, \bar{g})$.

Hypothesis 1 (H1). Both the number of social groups and the number of government groups are relatively stable; that is, the group size can be standardised to 1 . At time $t$, for the decisionmaking plan, the proportion of society choosing the Agree strategy is $x(t)$, and the proportion of the government choosing the Agree strategy is $y(t)$, resulting in $0 \leq x(t) \leq 1$ and $0 \leq y(t) \leq 1$.

Regarding the growth of bureaucracy, officials, as everyone else, pursue utility maximisation [39], and government composed of officials also pursues utility maximisation in the public decision-making process. As the head of public decision-making, the government holds decision-making power in the choice of public policy options. 
Hypothesis 2 (H2). If the government agrees, the public decision-making plan will be passed. The change in the benefits brought by the implementation of the plan to society is $E_{p}$, and the change in benefits to the government is $E_{g}$.

In the process of government and society's negotiation, if the public policy plan can fulfil the interests of society, society chooses the Agree strategy; otherwise, it chooses the Oppose strategy.

Hypothesis 3 (H3). The cost of the government organising public decision-making is $c_{g}$. The cost of society choosing strategy $p$ is $c_{p}$, and the cost of choosing strategy $\bar{p}$ is $c_{\bar{p}}$. If society chooses the Oppose strategy, more time and effort should be required, so $c_{\bar{p}}>c_{p}$.

Hypothesis $4 \mathbf{~ ( H 4 ) . ~ W h e n ~ s o c i e t y ~ c h o o s e s ~ s t r a t e g y ~} p$ and the government chooses strategy $\bar{g}$, the government is vulnerable to social suspicion due to inconsistent choices, resulting in a loss of reputation $r_{p}\left(r_{p}>0\right)$.

Hypothesis 5 (H5). When society chooses strategy $\bar{p}$ and the government chooses strategy $g$, the government's loss of reputation is $r_{\bar{p}}\left(r_{\bar{p}}>0\right)$. The government may modify the public policy plan; the probability of modification is $\omega(0 \leq \omega \leq 1)$, the cost is $m_{g}$, the increase in social benefits is $U_{p}\left(U_{p}>0\right)$, and changes in government revenue are denoted by $U_{g}$. The probability of modification is positively related to the proportion of social groups choosing strategy $\bar{p}$, assuming that $\omega=\omega(x)=\mu(1-x)$, in which $\mu>0$.

Hypothesis 6 (H6). If both the government and society choose the Oppose strategy, the public policy plan will not be passed, and the income of both players can be normalised to 0 .

The symbols of the relevant parameters are shown in Table 1.

Table 1. The symbols of the relevant parameters.

\begin{tabular}{cc}
\hline Symbol & Definition \\
\hline$x(t)$ & the proportion of society choosing the Agree strategy \\
$y(t)$ & the proportion of the government choosing the Agree strategy \\
$E_{p}$ & the society benefits change brought by the plan implementation \\
$E_{g}$ & the government benefits change brought by the plan implementation \\
$c_{g}$ & the cost of the government organising public decision-making \\
$c_{p}$ & the cost of society choosing strategy $p$ \\
$c_{\bar{p}}$ & the cost of society choosing strategy $\bar{p}$ \\
$r_{p}$ & the reputation loss of the government when society chooses strategy $p$ and the \\
$r_{\bar{p}}$ & government chooses strategy $\bar{g}$ \\
$\omega$ & the potation loss of the government when society chooses strategy $\bar{p}$ and the \\
$m_{g}$ & the cost of public policy plan modification \\
$U_{p}$ & the increase in social benefits by modifying the decision plan \\
$U_{g}$ & changes in government revenue by modifying the decision plan
\end{tabular}

Based on the above assumptions, the payoff matrix of society and the government is presented in Table 2.

Table 2. The Payoff Matrix of society and the government.

\begin{tabular}{|c|c|c|c|}
\hline \multirow{2}{*}{\multicolumn{2}{|c|}{$\begin{array}{l}\text { Game Players and } \\
\text { Their Strategies }\end{array}$}} & \multicolumn{2}{|l|}{ Government } \\
\hline & & Agree $(g)$ & Oppose $(\bar{g})$ \\
\hline society & $\begin{array}{c}\text { Agree }(p) \\
\text { Oppose }(\bar{p})\end{array}$ & $\begin{array}{c}\left(E_{p}-c_{p}, E_{g}-c_{g}\right) \\
\left(E_{p}+\omega U_{p}-c_{\bar{p}}, E_{g}+\omega\left(U_{g}-m_{g}\right)-c_{g}-r_{\bar{p}}\right)\end{array}$ & $\begin{array}{l}\left(-c_{p},-c_{g}-r_{p}\right) \\
\quad\left(-c_{\bar{p}},-c_{g}\right)\end{array}$ \\
\hline
\end{tabular}


Furthermore, the average payoff of society choosing strategy $p$ is $\pi_{p}=y \pi_{p g}+(1-y) \pi_{p \bar{g}}$, the average payoff of society choosing strategy $\bar{p}$ is $\pi_{\bar{p}}=y \pi_{\bar{p} g}+(1-y) \pi_{\overline{p g}}$, the average payoff of the government choosing strategy $g$ is $\pi_{g}=x \pi_{g p}+(1-x) \pi_{g \bar{p}}$, and the average payoff of the government choosing strategy $\bar{g}$ is $\pi_{\bar{g}}=x \pi_{\bar{g} p}+(1-x) \pi_{\overline{g p}}$.

In the public decision-making process, the government and society constantly adjust their behaviour according to the opponent's strategy through the mechanisms of imitation, learning and experimentation. Thus, game behaviour dynamically evolves. In both the government and society, strategies with better results than the average will be gradually adopted by more players, so the proportion of players who adopt various strategies in the group will change. Therefore, the replicator dynamics mechanism will be applied to analyse the dynamic evolutionary path of subject behaviour.

\subsection{Equilibrium Point of Evolution}

According to the above analysis, the average payoff of society is $\bar{\pi}_{p}=x \pi_{p}+(1-$ $x) \pi_{\bar{p}}$. The growth rate of the proportion of society choosing the Agree strategy is directly proportional to the difference between the payoff obtained by selecting this strategy and the average payoff of the group [26]; that is, the replicator dynamics equation of society choosing the Agree strategy is

$$
\dot{x}=x\left(\pi_{p}-\bar{\pi}_{p}\right)=x(1-x)\left(\pi_{p}-\pi_{\bar{p}}\right)=x(1-x)\left[c_{\bar{p}}-c_{p}-\mu U_{p}(1-x) y\right]
$$

Similarly, the replicator dynamics equation of the government choosing the Agree strategy is

$$
\dot{y}=y\left(\pi_{g}-\bar{\pi}_{g}\right)=y(1-y)\left(\pi_{g}-\pi_{\bar{g}}\right)=y(1-y)\left[E_{g}-r_{\bar{p}}+\left(r_{p}+r_{\bar{p}}\right) x+\mu\left(U_{g}-m_{g}\right)(1-x)^{2}\right]
$$

If we set $\lambda_{1}=c_{\bar{p}}-c_{p}, u_{1}=\mu U_{p}, F(x, y)=\lambda_{1}-u_{1}(1-x) y, \lambda_{2}=E_{g}-r_{\bar{p}}$, $u_{2}=\mu\left(U_{g}-m_{g}\right), r_{2}=r_{p}+r_{\bar{p}}$, and $G(x)=\lambda_{2}+r_{2} x+u_{2}(1-x)^{2}$, then $\lambda_{1}>0, u_{1}>0$, and $r_{2}>0 . \lambda_{1}$ can be understood as the fixed income of society choosing the Agree strategy instead of the Oppose strategy, while $\lambda_{2}$ can be seen as the fixed income of the government choosing the Agree strategy rather than the Oppose strategy.

$u_{1}$ is the maximum increase in social benefits from modifying the decision plan when society chooses the Oppose strategy and the government chooses the Agree strategy. $u_{2}$ represents the maximum increase in government benefits from modifying the decision plan when society chooses the Oppose strategy and the government chooses the Agree strategy. $r_{2}$ represents the relative reduction in the government's loss of reputation caused by the change in the proportion of society choosing the Agree strategy when the government chooses the Agree strategy. From Equations (1) and (2), we can obtain the two-dimensional dynamic System I of the interaction between society and the government, which is

$$
\left\{\begin{array}{c}
\dot{x}=x(1-x) F(x, y)=x(1-x)\left[\lambda_{1}-u_{1}(1-x) y\right] \\
\dot{y}=y(1-y) G(x)=y(1-y)\left[\lambda_{2}+r_{2} x+u_{2}(1-x)^{2}\right]
\end{array}\right.
$$

Let $\dot{x}=0$ and $\dot{y}=0$, and Proposition 1 can be obtained.

Proposition 1. (1) System I has four equilibrium points, $(0,0),(0,1),(1,0),(1,1)$, where a dual population adopts a pure strategy;

(2) When $\lambda_{1}<u_{1}$, System I has one equilibrium point $\left(1-\lambda_{1} / u_{1}, 1\right)$ where a single population adopts a pure strategy;

(3) There may be one equilibrium point $\left(x^{*}, y^{*}\right)$ or two equilibrium points $\left(x_{1}^{*}, y_{1}^{*}\right),\left(x_{2}^{*}, y_{2}^{*}\right)$ where a dual population adopts a mixed strategy, where $0<x^{*}=1-r_{2} / 2 u_{2}<1$, $0<y^{*}=2 \lambda_{1} u_{2} / u_{1} r_{2}<1,0<x_{1}^{*}=1-\left[r_{2}+\sqrt{r_{2}^{2}-4 u_{2}\left(r_{2}+\lambda_{2}\right)}\right] / 2 u_{2}<1$, $0<y_{1}^{*}=2 \lambda_{1} u_{2} / u_{1}\left[r_{2}+\sqrt{r_{2}^{2}-4 u_{2}\left(r_{2}+\lambda_{2}\right)}\right]<1,0<x_{2}^{*}=1-\left[r_{2}-\sqrt{r_{2}^{2}-4 u_{2}\left(r_{2}+\lambda_{2}\right)}\right]$ 
$/ 2 u_{2}<1,0<y_{2}^{*}=2 \lambda_{1} u_{2} / u_{1}\left[r_{2}-\sqrt{r_{2}^{2}-4 u_{2}\left(r_{2}+\lambda_{2}\right)}\right]<1$. The condition for the existence of the equilibrium point $\left(x^{*}, y^{*}\right)$ is $\lambda_{1}<u_{1}, r_{2}^{2}=4 u_{2}\left(r_{2}+\lambda_{2}\right),-r_{2}<\lambda_{2}<-r_{2} / 2,2 u_{2}>r_{2}>0$, the condition for the existence of the equilibrium point $\left(x_{1}^{*}, y_{1}^{*}\right)$ is $\left.\lambda_{1}<u_{1}, u_{2}>0, r_{2}^{2}\right\rangle 4 u_{2}\left(r_{2}+\right.$ $\left.\lambda_{2}\right), \lambda_{2}>-r_{2}$ or $\lambda_{1}<u_{1}, u_{2}>r_{2}>0, \lambda_{2}<-r_{2}$, and the condition for the existence of the equilibrium point $\left(x_{2}^{*}, y_{2}^{*}\right)$ is $\lambda_{1}<u_{1}, u_{2}>0, r_{2}^{2}>4 u_{2}\left(r_{2}+\lambda_{2}\right)$ or $\lambda_{1}<u_{1}, u_{2}<0, \lambda_{2}>-r_{2}$.

Proof. (1) For System I, when $x=0$ or $1, y=0$ or 1 , there is always $\dot{x}=0, \dot{y}=0$, so $(0,0)$, $(0,1),(1,0)$, and $(1,1)$ are the equilibrium points of system $\mathrm{I}$.

(2) When $y=1$, if $\lambda_{1}-u_{1}(1-x)=0$, there is also $\dot{x}=0, \dot{y}=0$, so if $\lambda_{1}<u_{1},\left(1-\lambda_{1} / u_{1}, 1\right)$, is the equilibrium point of System I.

(3) When $0<x<1,0<y<1$, if $F(x, y)=G(x)=0$, then $\dot{x}=0, \dot{y}=0$. By solving the equations, $\left(x^{*}, y^{*}\right),\left(x_{1}^{*}, y_{1}^{*}\right),\left(x_{2}^{*}, y_{2}^{*}\right)$ are the possible equilibrium points of System I. As $\lambda_{1}>0, u_{1}>0, r_{2}>0$, if equilibrium points exist, $r_{2}^{2} \geq 4 u_{2}\left(r_{2}+\lambda_{2}\right)$ must be satisfied. According to $0<x<1,0<y<1$, the conditions for the existence of equilibrium points can be obtained.

\subsection{Stability Analysis of Equilibrium Points}

The equilibrium points obtained via the replicator dynamics equation are not necessarily the ESSs of the system. According to the Friedman method, the stability of the system's equilibrium points can be judged by the local stability analysis of the Jacobian matrix. The Jacobian matrix of System I is

$$
J=\left[\begin{array}{cc}
(1-2 x)\left[\lambda_{1}-u_{1}(1-x) y\right]+u_{1} x(1-x) y & -u_{1} x(1-x)^{2} \\
\left(2 u_{2} x+r_{2}-2 u_{2}\right) y(1-y) & (1-2 y)\left[\lambda_{2}+r_{2} x+u_{2}(1-x)^{2}\right]
\end{array}\right]
$$

Calculating the determinant (Det) and trace (Tr) of matrix $\mathrm{J}$ at 8 equilibrium points in Proposition 1, the results are shown in Table 3.

Table 3. Determinants and Traces of Matrix J at Equilibrium Points.

\begin{tabular}{ccc}
\hline Equilibrium Points & Det J & Tr J \\
\hline$(0,0)$ & $\lambda_{1}\left(\lambda_{2}+u_{2}\right)$ & $\lambda_{1}+\lambda_{2}+u_{2}$ \\
$(0,1)$ & $-\left(\lambda_{1}-u_{1}\right)\left(\lambda_{2}+u_{2}\right)$ & $\lambda_{1}-u_{1}-\lambda_{2}-u_{2}$ \\
$(1,0)$ & $-\lambda_{1}\left(\lambda_{2}+r_{2}\right)$ & $-\lambda_{1}+\lambda_{2}+r_{2}$ \\
$(1,1)$ & $\lambda_{1}\left(\lambda_{2}+r_{2}\right)$ & $-\lambda_{1}-\lambda_{2}-r_{2}$ \\
$\left(1-\lambda_{1} / u_{1}, 1\right)$ & $-\lambda_{1}(1-$ & $\lambda_{1}\left(1-\lambda_{1} / u_{1}\right)-$ \\
$\left(x^{*}, y^{*}\right)$ & $\left.\lambda_{1} / u_{1}\right)\left[\lambda_{2}+r_{2}\left(1-\lambda_{1} / u_{1}\right)+u_{2}\left(\lambda_{1} / u_{1}\right)^{2}\right]$ & 0 \\
$\left(x_{1}^{*}, y_{1}^{*}\right)$ & 0 & $\left.\lambda_{2}+r_{2}\left(1-\lambda_{1} / u_{1}\right)+u_{2}\left(\lambda_{1} / u_{1}\right)^{2}\right]$ \\
$\left(x_{2}^{*}, y_{2}^{*}\right)$ & $\lambda_{1} x_{1}^{*}\left[\lambda_{1}-u_{1}\left(1-x_{1}^{*}\right)\right] \sqrt{r_{2}^{2}-4 u_{2}\left(r_{2}+\lambda_{2}\right)} / u_{1}$ & $\lambda_{1} x_{1}^{*}$ \\
\hline
\end{tabular}

According to the positive or negative outcome of the determinant and trace, the local stability of the equilibrium points of System I are judged, and the result is shown in Proposition 2.

Proposition 2. The possible ESSs of System I are $(0,1),(1,0)$, and $(1,1)$. Other equilibrium points are saddle points or unstable points. Among them, when $\lambda_{1}-u_{1}<0, \lambda_{2}+u_{2}>0,(0,1)$ is the ESS of System I; when $\lambda_{2}+r_{2}<0,(1,0)$ is the ESS; and when $\lambda_{2}+r_{2}>0,(1,1)$ is the ESS.

Proof. If Det $J>0$ and $\operatorname{Tr} J<0$ are satisfied, then the equilibrium point is locally stable; that is, ESS. Let Det $J>0, \operatorname{Tr} J<0$. It is easy to obtain the condition that equilibrium points $(0,1),(1,0)$, and $(1,1)$ in Proposition 2 are ESSs. 
For the equilibrium point $(0,0)$, when Det $J>0, \lambda_{2}+u_{2}>0$ due to $\lambda_{1}>0$, then $\operatorname{Tr} J>0$. Therefore, the point is unstable. When $\operatorname{Tr} J=0, \lambda_{1}+\lambda_{2}+u_{2}=0$, then the point is the saddle point. For the equilibrium point $\left(1-\lambda_{1} / u_{1}, 1\right)$, when Det $J>0$, $\lambda_{2}+r_{2}\left(1-\lambda_{1} / u_{1}\right)+u_{2}\left(\lambda_{1} / u_{1}\right)^{2}<0$, then $\operatorname{Tr} J>0$. Thus, the point is unstable. For the equilibrium point $\left(x^{*}, y^{*}\right),\left(x_{1}^{*}, y_{1}^{*}\right),\left(x_{2}^{*}, y_{2}^{*}\right)$, due to $\operatorname{Tr} J>0$, they are unstable, regardless of whether Det $J$ is positive or negative.

\subsection{Analysis of Evolutionary Game Results}

According to the equilibrium points' local stability analysis, by combining Propositions 1 and 2, System I has multiple and complex evolutionary paths. In this section, two types of situations are discussed in depth.

\subsubsection{Situation 1: $\lambda_{2}+r_{2}>0$}

Deduction 1. When $\lambda_{2}+r_{2}>0$, the possible ESSs are $(0,1)$ and $(1,1)$. Sub-situation 1: When $u_{1}>\lambda_{1}, \lambda_{2}+u_{2}>0$, there are two ESSs, as shown in Figures 1-3. Sub-situation 2: When $u_{1}>\lambda_{1}, \lambda_{2}+u_{2}<0$, or $u_{1}<\lambda_{1}, \lambda_{2}+u_{2}>0$, or $u_{1}<\lambda_{1}, \lambda_{2}+u_{2}<0$, there is a unique ESS $(1,1)$, as depicted in Figures $4-7$.

Deduction 1 illustrates that in the public decision-making process, regardless of the system's initial state, as long as public policy can increase the government's benefit, or the government's benefit reduction is less than the loss of reputation when society chooses the Agree strategy and the government chooses the Oppose strategy, the government will choose the Agree strategy and the public policy plan will be passed.
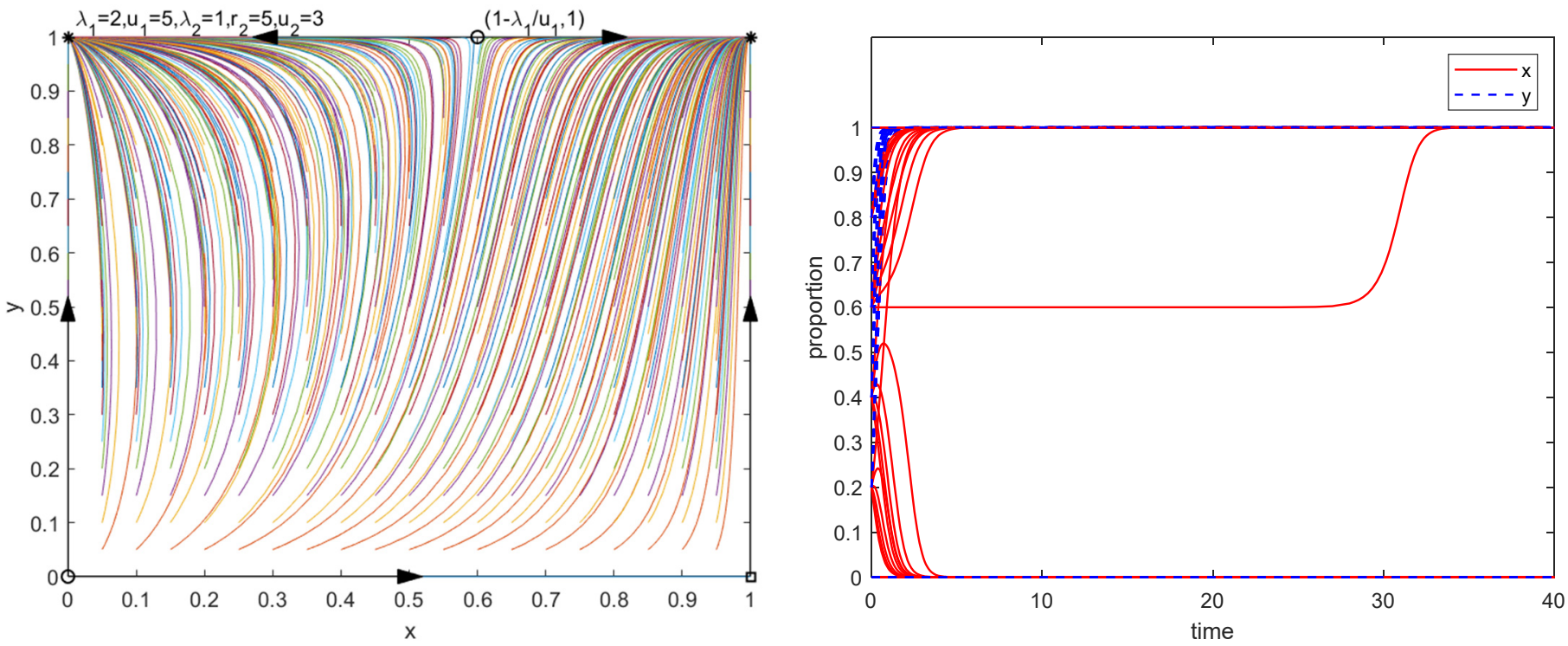

Figure 1. Dynamic evolutionary process (a) of System I in Sub-situation 1. (To visually display the evolutionary process of the system, different values are assigned to the parameters. In the evolutionary phase diagram, “ $\bigcirc$ ", “ $\square$ " and “*” represent the unstable point, saddle point and ESS, respectively, of the system. The same process is presented below).

In Sub-situation 1, when the maximum increase in social benefits is greater than the cost increase when society chooses Oppose $\left(u_{1}>\lambda_{1}\right)$, and the sum of the fixed income and the extreme change in benefits of the government when it chooses Agree is greater than $0\left(\lambda_{2}+u_{2}>0\right)$, the final strategy of society is determined by the initial state and mutual relationship of the dual population. At this time, System I has a non-ESS equilibrium point $\left(1-\lambda_{1} / u_{1}, 1\right)$, which will shift to the left as $\lambda_{1}$ increases or $u_{1}$ decreases and may remain stable for a relatively long period of time, as shown in Figure 1.

System I may have non-ESS equilibrium points $\left(x_{1}^{*}, y_{1}^{*}\right)$ and $\left(x_{2}^{*}, y_{2}^{*}\right)$ (see Figure 2) or $\left(x^{*}, y^{*}\right)$ (see Figure 3$)$. The curves formed by $(0,0)$ and $\left(1-\lambda_{1} / u_{1}, 1\right)$ (see Figure 1 ); 
$(0,0),\left(x_{1}^{*}, y_{1}^{*}\right),\left(x_{2}^{*}, y_{2}^{*}\right)$ and (Figure 2); or $(0,0),\left(x^{*}, y^{*}\right)$ and $\left(1-\lambda_{1} / u_{1}, 1\right)$ (see Figure 3 ) are the critical line of society's strategy convergence. On the left, society finally chooses Oppose; on the right, society finally chooses Agree. Therefore, the possibility of society choosing Agree can be enhanced by raising $\lambda_{1}$ or lowering $u_{1}$.
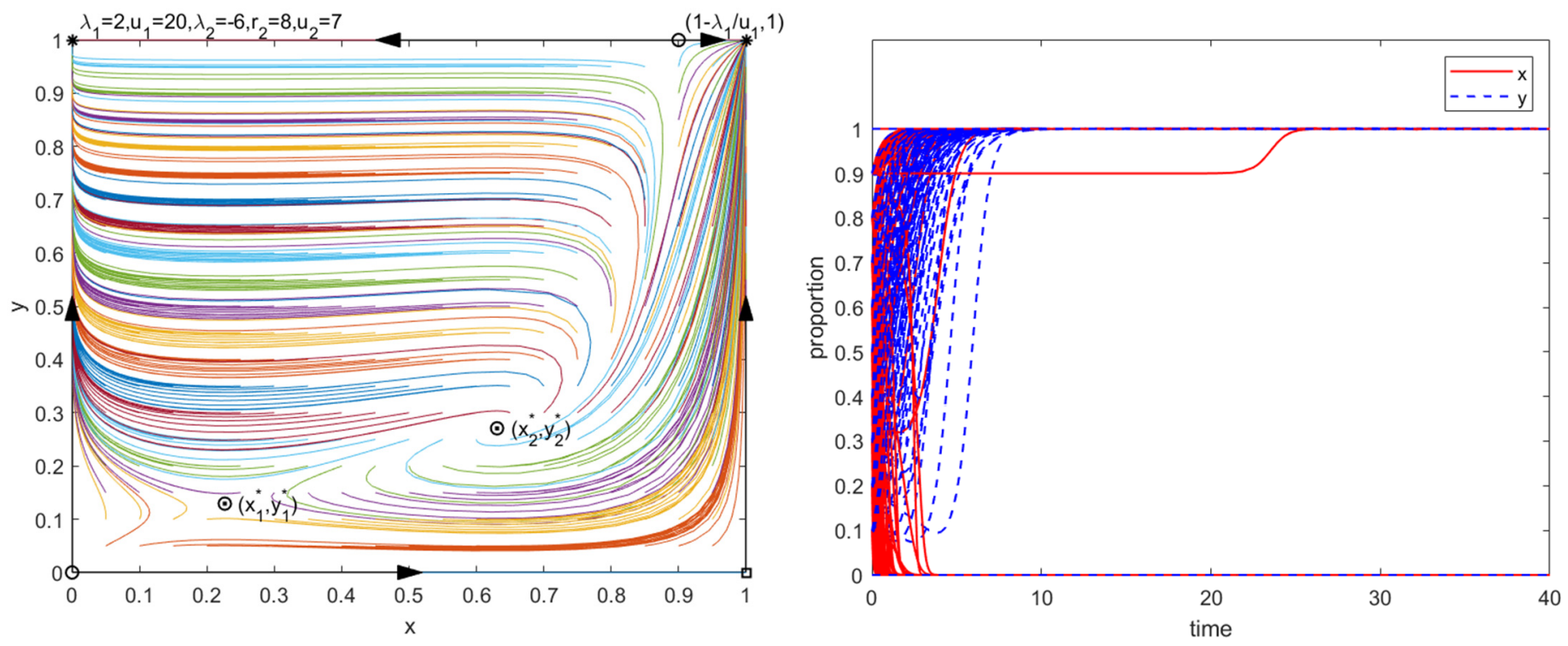

Figure 2. Dynamic evolutionary process (b) of System I in Sub-situation 1.
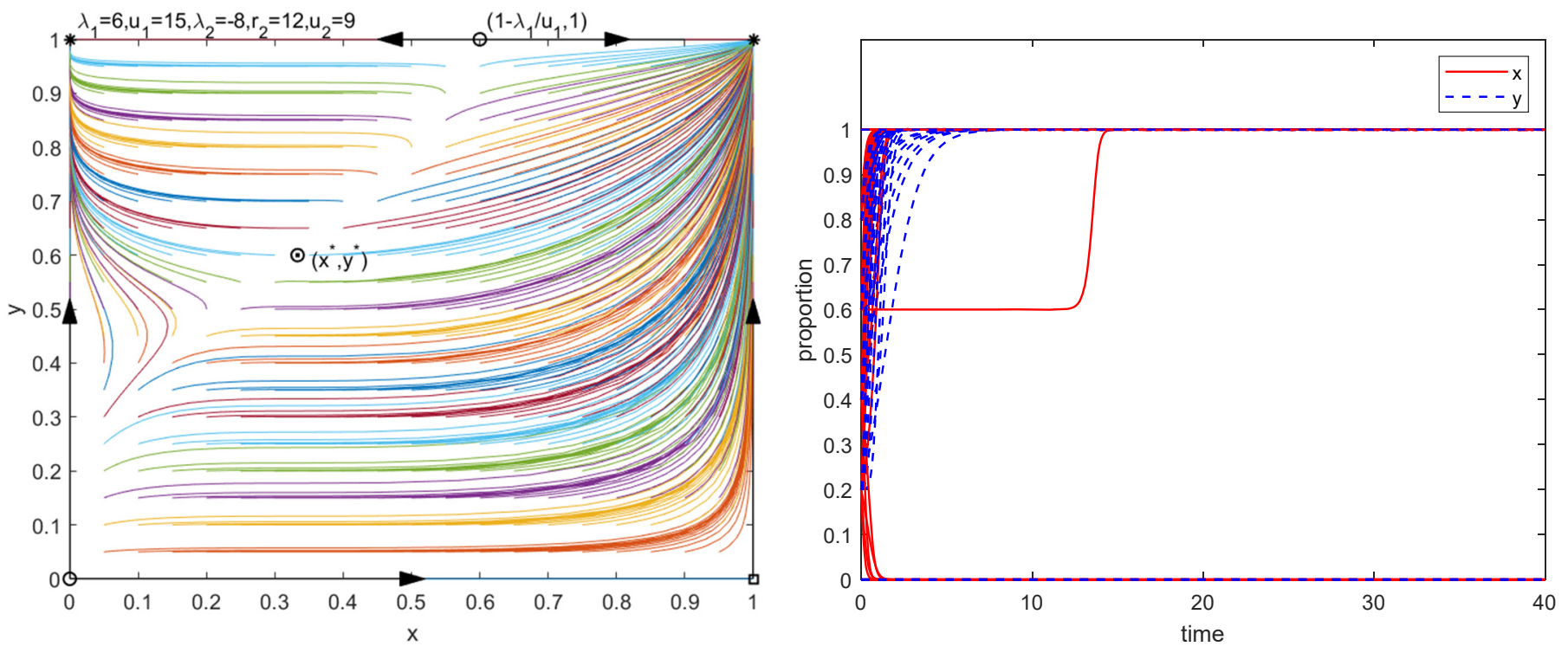

Figure 3. Dynamic evolutionary process (c) of System I in Sub-situation 1.

In Sub-situation 2, society finally chooses the Agree strategy. When the maximum increase in social benefits is greater than the increase in cost when society chooses Oppose $\left(u_{1}>\lambda_{1}\right)$, and the sum of the fixed income and the extreme change in benefits of the government when it chooses Agree is less than $0\left(\lambda_{2}+u_{2}<0\right)$, System I has a non-ESS equilibrium point $\left(1-\lambda_{1} / u_{1}, 1\right)$, as shown in Figure 4 . System I may have a non-ESS equilibrium point $\left(x_{2}^{*}, y_{2}^{*}\right)$, as portrayed in Figure 5. On the right side of the line between the equilibrium points, $\left(1-\lambda_{1} / u_{1}, 1\right)$ and $\left(x_{2}^{*}, y_{2}^{*}\right)$, society and the government tend to choose Agree. On the left side, the two groups initially tend to choose Oppose and finally choose Agree, and the length of time for System I to reach equilibrium is somewhat longer. 

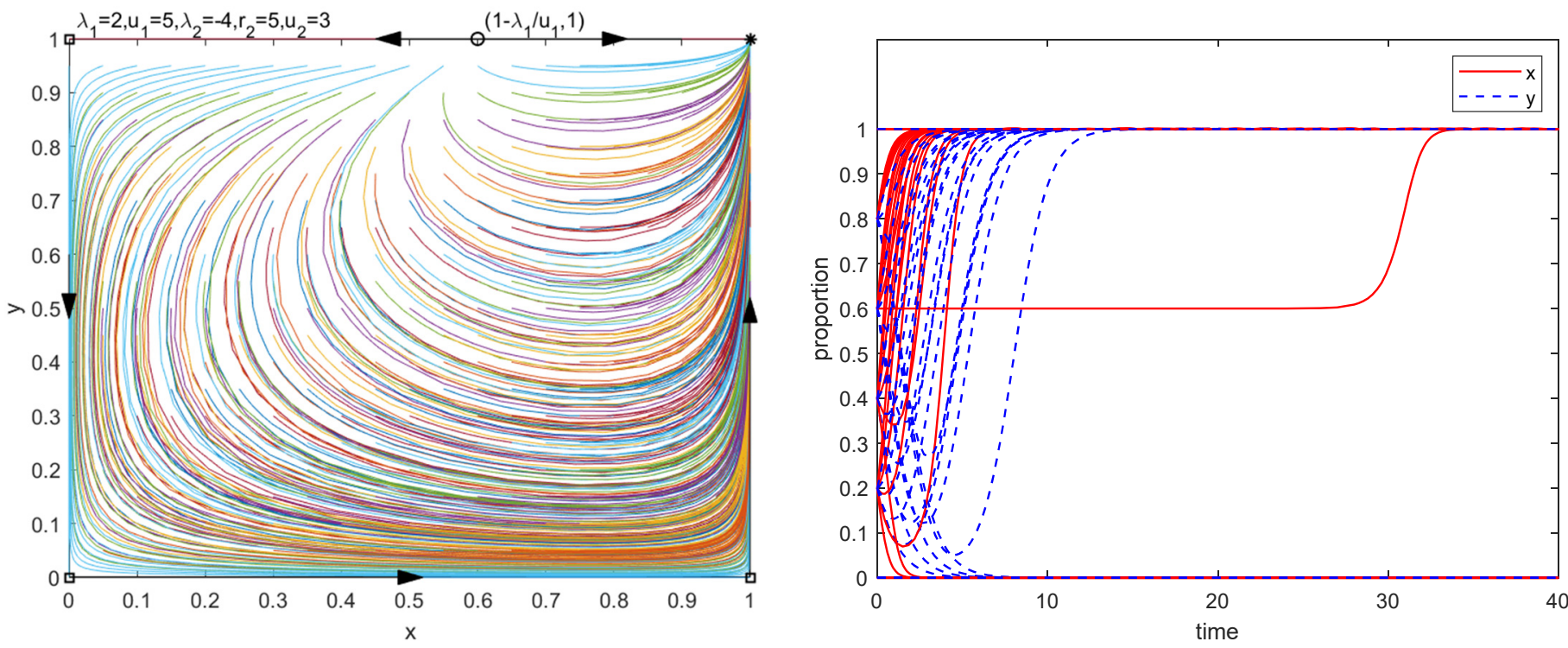

Figure 4. Dynamic evolutionary process (a) of System I in Sub-situation 2.
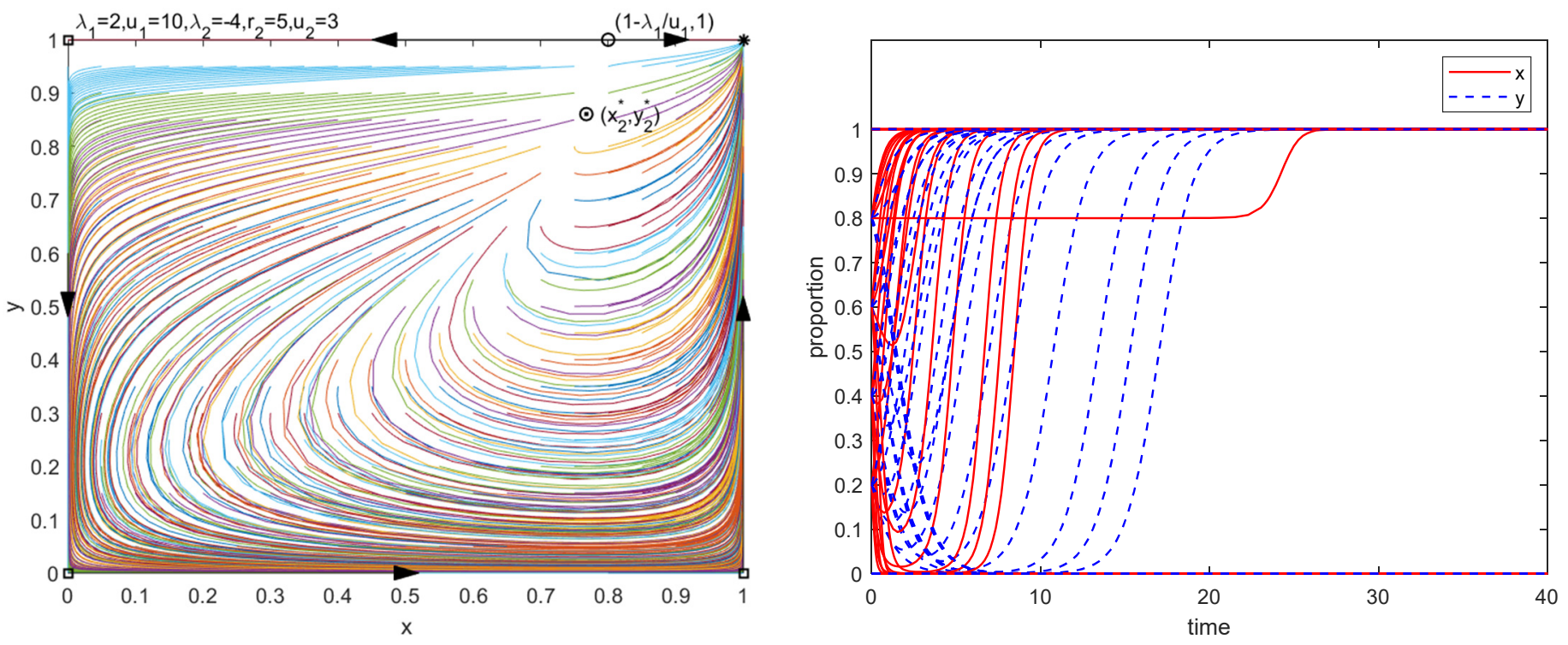

Figure 5. Dynamic evolution process (b) of System I in Sub-situation 2.

When the maximum increase in social benefits is less than the cost increase when society chooses Oppose $\left(u_{1}<\lambda_{1}\right)$ and the sum of the fixed income and the extreme change in benefits of the government when it chooses Agree is greater than $0\left(\lambda_{2}+u_{2}>0\right)$, the choice of both groups will converge towards Agree in a short time, as shown in Figure 6.

When the maximum increase in social benefits is less than the cost increase when society chooses Oppose $\left(u_{1}<\lambda_{1}\right)$ and the sum of the fixed income and the extreme change in benefits of the government when it chooses Agree is less than $0\left(\lambda_{2}+u_{2}<0\right)$, the choice of society will converge towards Agree in a short time, while the government will initially tend to choose Oppose and finally choose Agree, as outlined in Figure 7. 

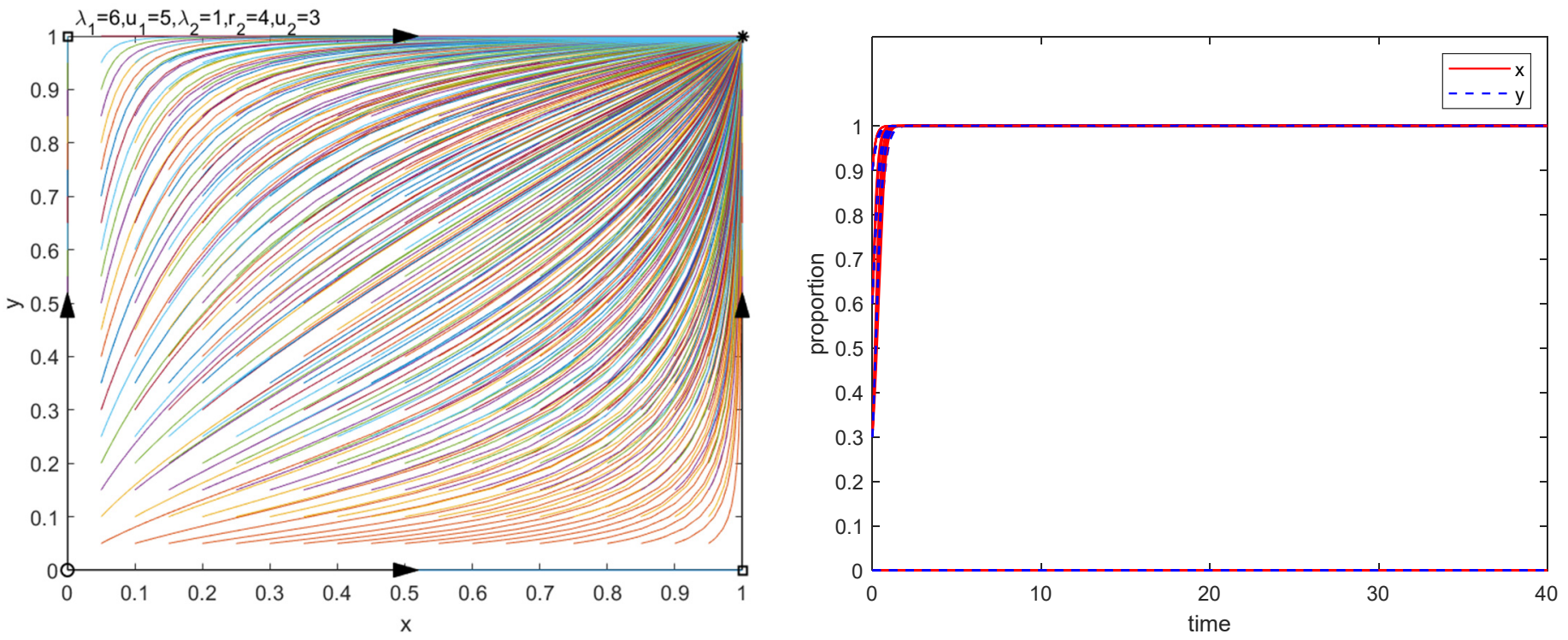

Figure 6. Dynamic evolutionary process (c) of System I in Sub-situation 2.
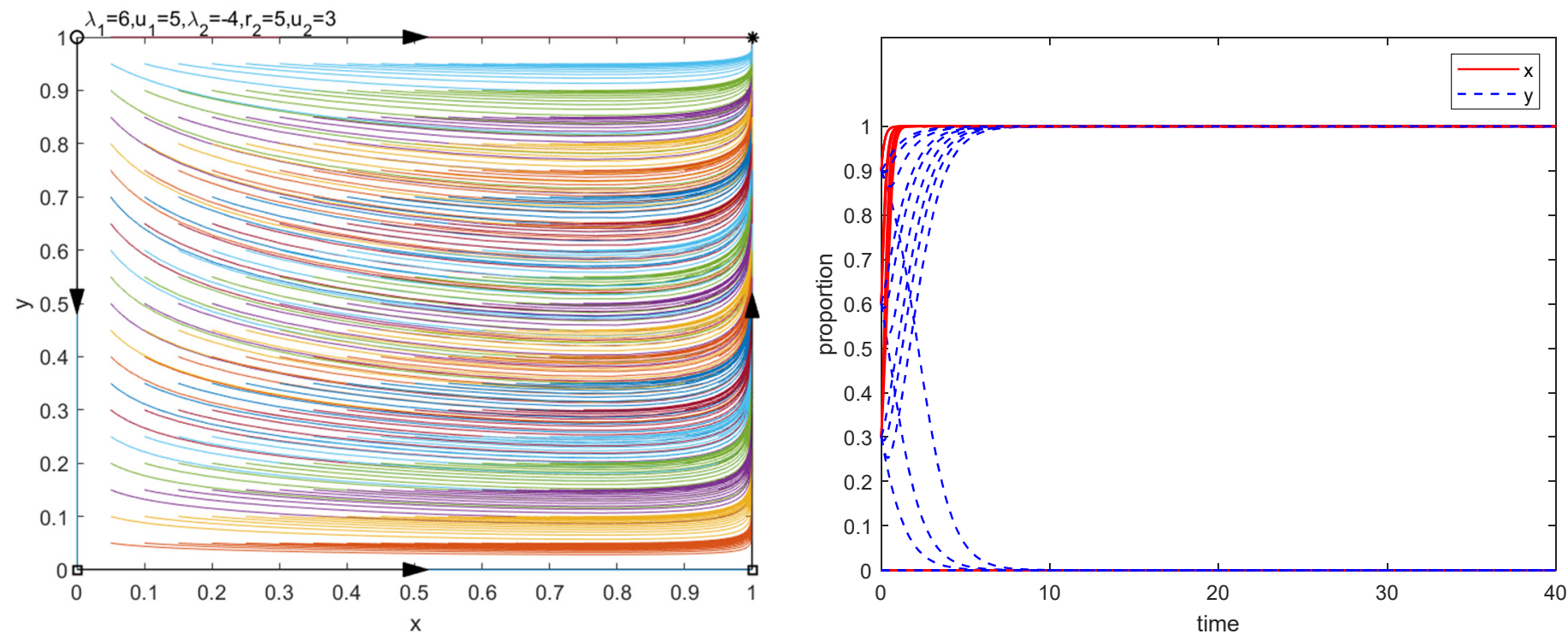

Figure 7. Dynamic evolutionary process (d) of System I in Sub-situation 2.

3.4.2. Situation 2: $\lambda_{2}+r_{2}<0$

Deduction 2. When $\lambda_{2}+r_{2}<0$, the possible ESSs are $(0,1)$ and $(1,0)$. Sub-situation 3: When $u_{1}>\lambda_{1}, u_{2}>r_{2}$, there are two ESSs, as displayed in Figure 8. Sub-situation 4: When $u_{1}>\lambda_{1}, \lambda_{2}+u_{2}<0$, or $u_{1}<\lambda_{1}, \lambda_{2}+u_{2}>0$, or $u_{1}<\lambda_{1}, \lambda_{2}+u_{2}<0$, there is a unique ESS $(1,0)$, as illustrated in Figures 9-11.

In Sub-situation 3, the government and society have conflicting opinions. At this time, System I has non-ESS equilibrium points $\left(1-\lambda_{1} / u_{1}, 1\right)$ and $\left(x_{1}^{*}, y_{1}^{*}\right)$. The curve formed by $(0,0),\left(x_{1}^{*}, y_{1}^{*}\right)$ and $\left(1-\lambda_{1} / u_{1}, 1\right)$ is the critical line of the government's strategy convergence. On the upper left of the curve, the government's strategy converges towards Agree, and on the lower right, it converges towards Oppose. 

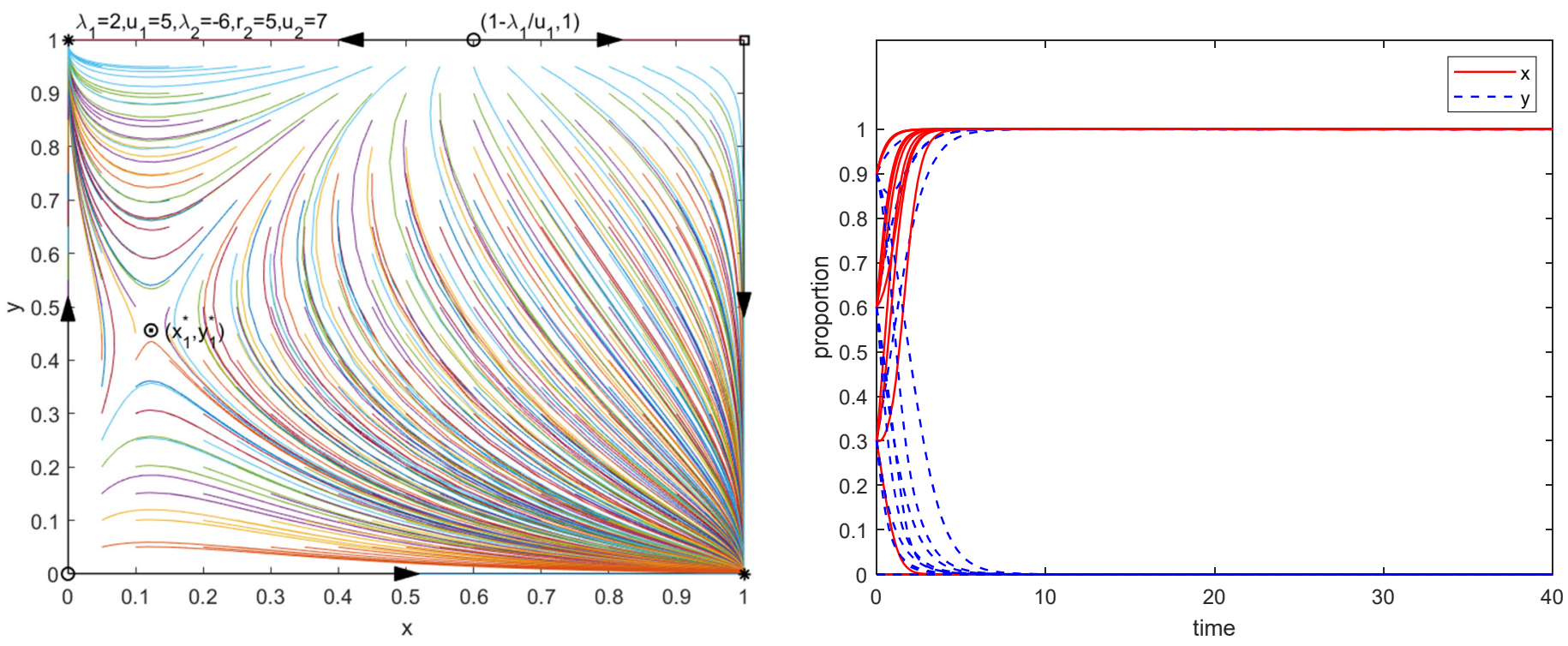

Figure 8. Dynamic evolutionary process of System I in Sub-situation 3.
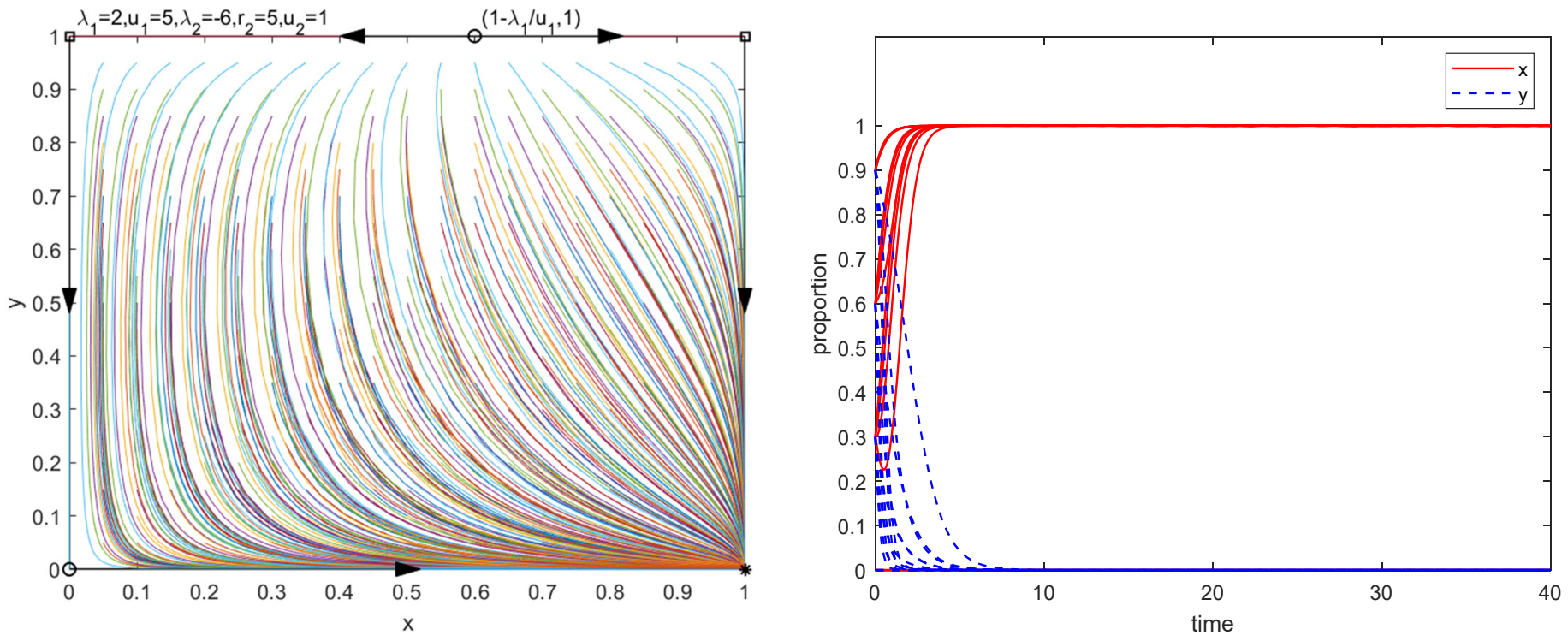

Figure 9. Dynamic evolutionary process (a) of System I in Sub-situation 4.

In Sub-situation 4, society finally chooses the Agree strategy, the government chooses the Oppose strategy, and the public policy plan will be rejected. When the maximum increase in social benefits is greater than the cost increase when society chooses Oppose $\left(u_{1}>\lambda_{1}\right)$ and the sum of the fixed income and the extreme change in benefits of the government when it chooses Agree is less than $0\left(\lambda_{2}+u_{2}<0\right)$, System I has a non-ESS equilibrium point $\left(1-\lambda_{1} / u_{1}, 1\right)$. On the right side, society tends to choose Agree. On its left side, society initially tends to choose Oppose and finally chooses Agree. The government tends to choose Oppose, as portrayed in Figure 9.

When the maximum increase in social benefits is less than the cost increase when society chooses Oppose $\left(u_{1}<\lambda_{1}\right)$, and the sum of the fixed income and the extreme change in benefits of the government when it chooses Agree is greater than $0\left(\lambda_{2}+u_{2}>0\right)$, society tends to choose Agree, while the government either tends to choose Agree or to choose Oppose and eventually converges towards Agree, as outlined in Figure 10.

When the maximum increase in social benefits is less than the cost increase when society chooses Oppose $\left(u_{1}<\lambda_{1}\right)$, and the sum of the fixed income and the extreme change 
in benefits of the government when it chooses Agree is less than $0\left(\lambda_{2}+u_{2}<0\right)$, society tends to choose Agree, and the government tends to choose Oppose, as shown in Figure 11.
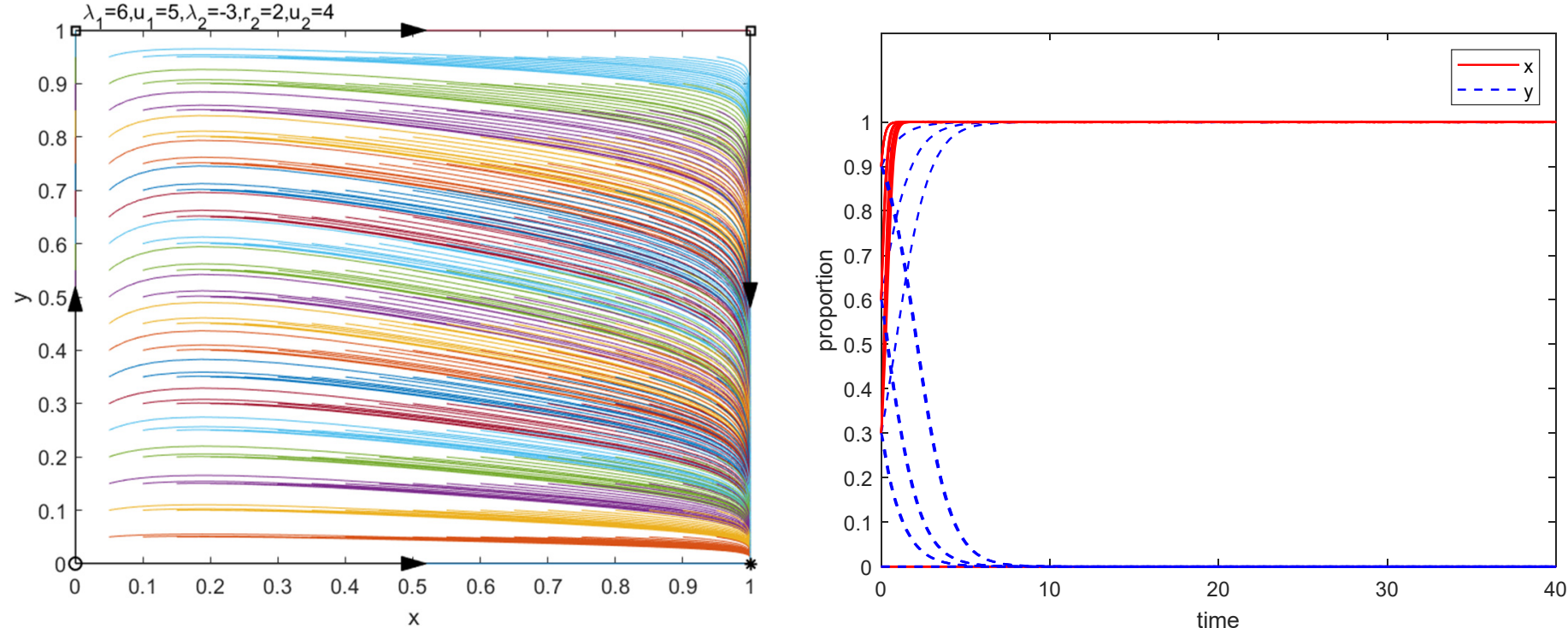

Figure 10. Dynamic evolutionary process (b) of System I in Sub-situation 4.
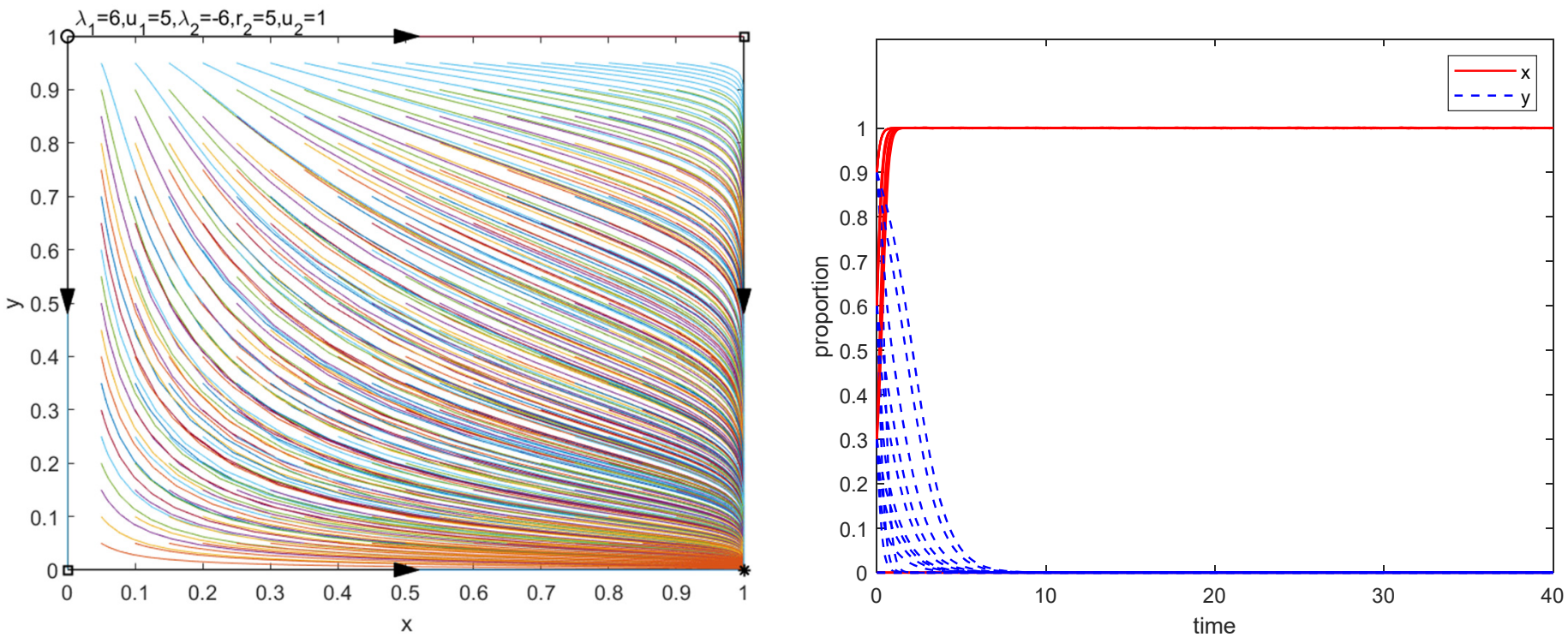

Figure 11. Dynamic evolutionary process (c) of System I in Sub-situation 4.

\subsection{Discussion of Evolutionary Game Results}

Through the above analysis, Conclusion 1 and Conclusion 2 can be obtained.

Conclusion 1. The necessary and sufficient condition that the Agree strategy is the only choice for the government in ESS is $\lambda_{2}+r_{2}>0$.

$E_{g}+r_{p}>0$ can be derived from $\lambda_{2}+r_{2}>0$. Because $r_{p}>0$, as long as $E_{g}>0$, that is, the plan can increase government benefits, or $E_{g}<0, r_{p}>-E_{g}$, that is, although the plan will reduce government benefits, and the loss of reputation that results from choosing the Oppose strategy is greater than the reduction in benefits, and after a certain period of repeated imitation, learning, and experimentation, the government finally chooses the Agree strategy. 
Conclusion 2. The necessary and sufficient condition that the Agree strategy is the only choice for society in ESS is $u_{1}<\lambda_{1}, \lambda_{2}+u_{2}>0$, or $u_{1}<\lambda_{1}, \lambda_{2}+u_{2}<0$, or $u_{1}>\lambda_{1}, \lambda_{2}+u_{2}<0$

$\mu U_{p}<c_{\bar{p}}-c_{p}$ can be derived from $u_{1}<\lambda_{1}$; that is, the increase in social benefits due to modifying the policy plan is less than the increase in the cost of choosing the Oppose strategy; after a certain period of repeated imitation, learning, and experimentation, the bounded rational society finally chooses the Agree strategy. Next, $\mu U_{p}>c_{\bar{p}}-c_{p}$ can be derived from $u_{1}>\lambda_{1}$, and $E_{g}+\mu\left(U_{g}-m_{g}\right)<r_{\bar{p}}$ can be derived from $\lambda_{2}+u_{2}<0$; that is, when the increase in social benefits due to modifying the policy plan is greater than the increase in the cost of choosing the Oppose strategy, and the government's benefit is less than its loss of reputation from choosing the Agree strategy, society may initially choose the Oppose strategy, but after a certain period of repeated imitation, learning, and experimentation, the bounded rational society finally chooses the Agree strategy.

The sufficient and unnecessary condition for System I to reach the desired state (both society and the government choose the Agree strategy) is $E_{g}+r_{p}>0, \mu U_{p}<c_{\bar{p}}-c_{p}$, or $E_{g}+r_{p}>0, \mu U_{p}>c_{\bar{p}}-c_{p}, E_{g}+\mu\left(U_{g}-m_{g}\right)<r_{\bar{p}}$, and the time for System I to reach equilibrium is relatively longer in the second case. Therefore, the policy plan can be improved by fully considering the interests of multiple subjects in the design stage of the policy plan to reduce the possibility of plan modification $\mu$ and increase social benefits $U_{p}$, thereby effectively improving the efficiency of public decision making.

In addition, when $E_{g}+r_{p}>0, \mu U_{p}>c_{\bar{p}}-c_{p}, E_{g}+\mu\left(U_{g}-m_{g}\right)>r_{\bar{p}}$, System I may reach the desired state. At this time, the likelihood that System I will reach the desired state can be increased by reducing the cost of society choosing the Agree strategy $c_{p}$, the possibility of plan modification $\mu$ and social income increment $U_{p}$.

\section{Case Study}

Taking the waste incineration projects in Yuhang and Chaonan as examples, this section will analyse the transformation of the mode of decision making regarding China's NIMBY facilities and the evolution of the strategy adopted by the government and society.

\subsection{Case 1: Yuhang Waste Incineration Project}

From 2007 to 2016, the domestic waste output of Hangzhou (including Xiaoshan and Yuhang) increased from 1.6194 million tonnes to 3.7878 million tonnes, with an annual growth rate of $9.9 \%$. There was only one waste incineration plant in the western part of Hangzhou. Due to limited processing capacity and the lack of land for expansion, new waste incineration facilities are urgently needed. On 29 March 2014, the Modification of the Specialised Plan Revision of Hangzhou Environmental Sanitation (2008-2020) was published, which indicated that a domestic waste incineration power plant would be built in Jiufeng Village, Zhongtai Township, Yuhang District. However, the location of the site was only marked with a dot in the planning diagram, the content of the public announcement was basic and vague, and the information was incomplete.

The project site was located close to four villages adjacent to waterworks and reservoirs. The public was concerned that the project would destroy the local ecology and pollute the environment, affecting people's physical and mental health, the value of real estate, and the development of local industry. On 24 April 2014, the surrounding villagers and urban residents submitted a joint petition to the project (with more than 20,000 people) and an application (52 people) for a hearing with the Planning Bureau. They received a "form" written reply on the same day. However, the public did not receive a reply after the planned publicity deadline. From 1 to 6 May, more than 200 villagers went to the street office to petition and demonstrate collectively every day. On the 7 th, some measuring instruments were transported to the village, and news about the secret start of the project spread, which intensified the opposition and triggered a large-scale gathering of people at the proposed project site and the street office. 
On the 9th, the district government issued a notice stating that the project would not start until it fulfilled the required legal procedures and obtained everyone's understanding and support, and that the local people would be invited to participate in the entire process in the early stages of the project, thus signaling hope so that the masses would not gather again. The announcement did not relieve the people's anxiety and generalised belief [40] but instead prompted violent, destructive mass incidents the next day. Nearly 5000 people blocked provincial roads and highways, resulting in traffic disruption. Dozens of policemen and civilians were injured, and several police cars and other vehicles were destroyed.

This project was led by the Hangzhou Municipal Government. The government believed that the geographic environment, urban planning and other factors, as well as the impact on transportation and people's lives, had been comprehensively considered and that the decision-making process for the project was scientific, but it had been resisted by the public, highlighting the closed decision-making problem. As early as August 2012, the Municipal Development and Reform Commission, the Environmental Protection Bureau, the Planning Bureau and other departments set up a leading group for the construction of the Jiufeng Waste Incineration Plant. According to the principle of localisation management, the Yuhang District Government was responsible for promoting project construction. In October 2013, Hangzhou Jiufeng Environmental Energy Co., Ltd. (Hangzhou, China) was established by the Hangzhou Thermal Power Group, Environmental Group and Road and Bridge Group, which was responsible for project construction. The project information was officially announced in 2014, and there was dramatic asymmetry between the information known by the local people affected by the project and that known by the decision makers. In the process of receiving petitions from people opposed to the project, the relevant government departments did not communicate in a timely manner with the public but rather were concerned that the expansion of the conflict would affect social stability and suppress the expression of public opinion, indicating that the government had limited rationally in project decision making and in their response to public opinion. The publicity system, which was intended to expand public participation, was only symbolically implemented. The publicly institutionalised expression of the participation demands and objections did not receive a substantive response and eventually evolved into resistive participation in violent mass incidents.

After the mass incident, the local government realised that the construction of NIMBY facilities must be accepted and recognised by the people. It then addressed the crux of the problem, focusing on the innovation and implementation of the open consultative decision-making model.

A Project Office of Special Leading Group for Major Livelihood Projects was substantively established by reallocating members of functional departments such as Environmental Protection, Land, Development and Reform, Construction, Urban Management, Administrative Services, Finance, and Transportation, which had created four groups to handle various issues, i.e., comprehensive coordination, mass work, technology, and policies. At the same time, the city's project office was established and was responsible for communication and coordination with provincial-related functional departments such as development and reform, and land and environmental protection. In the negotiated decision making of the Yuhang waste incineration project, the government included district and municipal governments, project offices, and related functional departments, and society includes mainly residents of surrounding villages that may be affected by the project.

From May to November 2014, the district government organised a sub-district office staff visit to the villages to collect opinions from the public and to provide feedback to the project office. The relevant functional departments were instructed to address any problems, and the results were fed back to the public by the project office. For example, in response to the demolition opinions of more than 2000 households within $3 \mathrm{~km}$ of project, the project office instructed the sub-district to resolve the issue and reported to the district committee and district government. The project office's mass working group and sub-district were responsible for communicating with the public and eventually promised to complete the 
demolition gradually. The government decision-making department actively invited the public to participate in the preliminary work of the project, allowing the public to compare the construction and operation standards of similar projects, participate in the selection of the project construction unit, and to finally select an enterprise with construction and operation experience.

In response to public doubts about the standards for waste treatment facilities and project operation risks, from July to September 2014, the district government successively organised 82 groups of more than 4000 people, accounting for $80 \%$ of the farmers in the four villages around the project, to travel Guangzhou, Nanjing, Suzhou, Changzhou and other places to inspect similar projects. By understanding the handling of pollutants and visiting local residents, people's cognitive bias was eliminated.

In response to the public's concern that the project's actual operation and management could not meet the design expectations and government supervision would not be in place, a third-party supervision mechanism was introduced, a mode of supervision by residents at any time was established, and the government promised to immediately shut down the waste-incineration power plant in the event of stolen or leaked discharge to relieve the public's anxiety.

In addition, the benefit compensation plan was determined, according to which most of the compensation for waste disposal in different places paid by the garbage-producing area would be allocated to the sub-district for public services and livelihood projects such as roads, public transportation, drinking water, culture and sports. These efforts would be implemented in advance and support plans to develop tourist attractions, and smart industrial parks were to be constructed.

In the game between the government and society, the project decision-making plan was continuously revised and improved. The granting of demands regarding the demolition, choice of construction and operation entities, improvement of emissions standards, and innovation of supervision mechanisms reduced the environmental risks and impacts of the projects and eliminated the public's risk perception bias. The benefit compensation mechanism and the development of opportunities and prospects gave people a sense of achievement. After nearly one year of communication and negotiation, the income of social subjects increased significantly, and the project was able to significantly increase the income of the government and the entire society. Additionally, the government and society finally reached a consensus on the decision-making plan for the project. At the end of March 2015, through hydrological monitoring, a stability assessment (environmental assessment) public surveys, full publicity of environmental assessments, geological exploration and preliminary design approval, all the work for approval and construction was completed, and the legal conditions for starting construction were met. On 14 April 2015, project construction began. That is, the two-dimensional dynamic system of interaction between society and government evolved to a mutually agreed upon expectation, and the NIMBY dilemma was resolved.

\subsection{Case 2: Chaonan Waste Incineration Project}

The waste incineration power plant project in Chaonan District of Shantou City progressed smoothly after receiving unanimous approval from the local people. This progression was attributed to the democratic decision-making model in which multiple subjects participated.

In the preparatory stage, in 2013, the government listed the plant as the number one livelihood project and established a project-construction leading group and joint-meeting system to study possible problems and provide systematic solutions.

During the site-selection stage, each town (sub-district) selected an available site, and the district urban management bureau invited experts to provide a scientific demonstration to select the site based on the principle of minimising negative impacts. Three groups of villagers were organised to inspect the waste-incineration power plants operated by the contractor for the project, so as to obtain first-hand experience of the operation, and people's cognitive biases were eliminated by word of mouth. At the same time, the 
technical standards of flue-gas treatment were improved, the design scheme was optimised to minimise negative impacts, and the public's concerns were dispelled.

The formulation of the plan for compensation for land acquisition involved extensive solicitation and listening to the opinions of the people, with reference to the compensation standards for expressway land acquisition in the area. This process resulted in the compensation being paid in one lump sum. Additionally, new roads, bridges, school buildings and other infrastructure and public welfare projects were planned, and the indicators of village industrial land and homestead land were increased.

During the operational period, medical and endowment insurance would be paid to the villagers, and fixed compensation would be given annually. Through the transfer of certain expected operating income by the enterprise, the government provided more comprehensive public services, aiming to eliminate the villagers' relative deprivation by land expropriation, possible changes in the living environment, and the substantial impact on road traffic. Through the coordinated and balanced distribution of benefit, a decision-making consensus was finally reached, and construction started smoothly at the end of 2014 .

\subsection{Case Study}

Since real data are difficult to obtain, the evolution path of the two-dimensional dynamic system of interaction between the government and society in the above two cases will be discussed in this part.

The Yuhang Waste Incineration Project began with a closed decision-making process in 2012, which triggered the resistance of the people. Then, the decision-making process was opened to allow communication and negotiation with the people, and a consensus was reached in 2015. The evolutionary path of the two-dimensional dynamic system of interaction between society and the government belongs to Sub-situation 2(a) or (b). That is, when the increase in society's benefits of choosing the Oppose strategy is greater than the increase in costs, and the government's benefits of choosing the Agree strategy are lower than the loss of reputation, both society and the government ultimately choose the Agree strategy, but it takes longer for the system to attain equilibrium.

The Chaonan Waste Incineration Project adopted a consultative decision-making model from the beginning. The project's decision-making process was significantly shorter. The evolutionary path of the two-dimensional dynamic system of interaction between society and the government belongs to Sub-situation 2(c). That is, when society's increase in benefits of choosing the Oppose strategy is lower than the increase in costs, and the government's loss of reputation in choosing the Agree strategy is low, society and the government will converge towards the Agree strategy within a brief period of time.

It has been found that case 1 belongs to Sub-situation 2(a) or (b), and case 2 belongs to Sub-situation 2(c), which were discussed in Section 3.4. This result shows that the "participation-negotiation-consensus" decision-making model can achieve a balance between individuals' demands and public rationality; thus, the decision making and construction of NIMBY facilities can be implemented smoothly with public approval.

\section{Public Decision-Making Mechanism Optimisation Strategy}

Through the above evolutionary game analysis and case study, the decision-making mechanism can be optimised from the following four aspects to avoid the NIMBY dilemma in the network society.

\subsection{Innovation and Implementation of the Negotiation Decision-Making Model}

In the network society, the public can communicate directly with the government's decision-making departments, and public opinion has a prominent role in social governance. However, excessive participation may alienate the public from taking part in the decision-making system. It is necessary to adhere to the principles of openness, science and democracy; establish a classified and hierarchical institutionalised participation mecha- 
nism; enhance the transparency, participation and responsiveness of decision-making; and achieve fair participation and just decision-making.

The government's right to determine policy issues has been weakened in virtual society, but whether social issues can be incorporated into public decision-making is still determined by the government [41]. In the agenda-setting stage, the decision-making department should strengthen the recognition of social issues, constructing government agenda from the top down. At the same time, social issues could be incorporated into the decision-making agenda from the bottom up through the public agenda by encouraging the active role of experts, social organisations, the public and the media. Thus, the sources of decision-making issues can be expanded.

In the policy plan design stage, modern technology and scientific decision-making methods can be used to improve the decision-making information and intellectual support system. The policy plan should be researched and formulated based on a decision to fully understand people's interests, demands and opinions and the aggregated preferences of social groups to increase social benefits $\left(E_{p}\right)$, reduce possibility $(\mu)$ and increase the social benefits $\left(U_{p}\right)$ of plan modification to effectively bridge the gap between public opinion, knowledge and policy.

In the policy-plan selection stage, communication and negotiation between decisionmaking departments and society should be strengthened; third-party institutions can be introduced to evaluate the value, effect, risk and feasibility of alternatives; and social opinions should be incorporated through comprehensive use of oral, written and online communication. Through an overall consideration of benefits, efficiency, fairness, responsiveness and appropriateness, policy options will be optimised to enhance social identity $(x)$.

In the policy implementation stage, social organisations, the public, and the media should be allowed to monitor the implementation of policy, policy dynamics information and new issues should be communicated, and closed-loop control of decision making should be achieved to fully realise the effectiveness of public policy.

\subsection{Improving Public Decision-Making Ability}

In the network society, improper public decision making and mistakes have a wider impact, the loss of reputation is greater, and the opportunity cost of policy modification is large. It is necessary to establish a long-term inspection mechanism for public policy effectiveness and a continuous learning mechanism for government policymakers, strengthen special training on scientific and democratic decision-making, establish correct value orientation and public orientation and improve the government's ability to make public decisions.

The public interest is based on individuals' interests. Public decision making should realise the expression, concentration and balance of diverse interests. However, in practice, it is difficult to balance and realise all interests and demands, which may trigger public opposition. Individuals' interests and demands show blindness and accidental value judgements, and decentralised and atomised demands lack typicality and representativeness and consequently, are difficult to accurately identify and fully address. Thus, they have little influence on public decision making $(\mu)$.

The government can integrate social organisations' interests and centralise their expression of demands by summarising and coordinating different interests and demands, collecting and refining scattered opinions and suggestions, centralising their expression in an organised and professional manner, and requesting that the decision-making department provide feedback on them. In this way, the government can not only effectively reduce the cost of individuals expressing objections $\left(c_{\bar{p}}\right)$ but also increase the possibility of policy plan modification $(\mu)$, thereby substantially affecting the formulation of public policies and sharing in the benefits of collective action $\left(U_{p}\right)$. 


\subsection{Optimising the Comprehensive Coordination Mechanism of Interests}

Public decision making involves complex interests that are in obvious tension. It is necessary to fully consider stakeholders' demands and achieve a balanced distribution of interests through full negotiation. The decision-making department should clarify the decision-making goals and benefits orientation, improve the decision-making consultation system, and improve the benefits coordination and compensation mechanism. Based on fully analysing and clarifying the interests of all parties, personal interests and public interests, partial interests and overall interests, and current interests and long-term interests should be coordinated through consultations in accordance with the prescribed procedures. The distribution of interests will be optimised, and the balanced distribution of interests and maximisation of public interests will be realised. The sense of gain for groups whose interests have been harmed can be enhanced by providing fair, reasonable compensation in full and ensure that this is in place $\left(E_{p}\right)$ through the comprehensive use of ecological compensation, employment absorption, infrastructure construction and public service supply. It is necessary to provide a mechanism to address and arbitrate conflicts of interest, standardise the negotiation process and ensure the fairness and rationality of the negotiation results. At the same time, we need to improve relevant laws and regulations, strengthen the construction of social norms, guide social subjects to rationally set interest goals, consciously adjust interest needs, standardise interest behaviours, and increase the cost of noninstitutionalised expression of objections $\left(c_{\bar{p}}\right)$, which will motivate the public to express their demands in an institutionalised manner.

\subsection{Building a Public Decision-Making Service Platform}

With modern information technologies such as mobile internet, big data, cloud computing and blockchain, a public decision-making service platform should be built to provide functions such as the release and browsing of decision-making information, public-opinion mining and analysis, and decision-making performance evaluation. The platform can serve as a field of participation for stakeholders such as governments, enterprises, social organisations and the public. On the platform, public decision-making information will be made public, and decision-making process can be dynamically displayed through the innovative use of visualisation methods, enterprises, and social organisations. The public can be encouraged to participate in decision-making, which will effectively reduce the cost of decision making by organisations $\left(c_{g}\right)$.

Social subjects can easily propose public policy needs, obtain public decision-making information, and fully express opinions on policy plans and implementation, which will significantly reduce decision-making participation costs $\left(c_{p}\right)$ and increase enthusiasm for participation. Subjects can interact conveniently, significantly reducing society's cost of choosing the Oppose strategy $\left(c_{\bar{p}}\right)$. The decision-making department can directly obtain opposing opinions and then organise experts and technicians to modify policy plans, which will reduce modification costs $\left(m_{g}\right)$.

Through public-opinion mining and analysis, the decision-making department can perceive and grasp public opinion in real time, uncover problems in the policy implementation process and make timely and dynamic adjustments. Giving a role to the functions of social media's interactivity and immediacy, personalisation and community building will promote interaction between participants and improve decision-making communication and consultation mechanisms to achieve mutual trust between the government and society and finally reach a consensus on decision making, which can avoid the government's loss of reputation $\left(r_{p}, r_{\bar{p}}\right)$.

\section{Conclusions}

The dilemma of the construction of NIMBY facilities indicates that the closed public decision-making model is unsustainable, and innovation in the ways and channels of social participation in the network society has allowed for the realisation of the negotiated decision-making model of extensive social participation. Public decision making, led by the 
government and by social participation is a dynamic game process in which the government and participants repeatedly negotiate and seek a balance of interests. Evolutionary stability depends on the relationship between the change in government revenue and the loss of reputation, and the relationship between the cost of society choosing the Oppose strategy and the increase in benefits brought by plan modification.

Through an evolutionary game analysis and case analysis, this study found that when society chooses the Oppose strategy, in case (1), the increase in social benefits obtained by plan modification is greater than the increase in costs, and the government's benefits when it chooses the Agree strategy are less than its loss of reputation, or, in case (2), if the increase in social benefits obtained by plan modification is less than the increase in costs, society will eventually choose the Agree strategy, but it takes longer for the system to reach equilibrium in case (1).

Therefore, a public decision-making service platform can be built. Based on the platform, the interests and opinions of multiple subjects can be fully considered in the policy plan design stage to improve the policy plan and enhance the increase in social benefits, and the organisational cost and participation cost of decision-making can be reduced, as can the possibility and cost of plan modification. In the stage of plan selection, communication and negotiation between subjects can be strengthened to enhance social identity, thereby avoiding the loss of government reputation and reducing implementation resistance. Finally, in the stage of public policy implementation, social supervision is useful, to achieve closed-loop control of public decision-making and exert the effective force of public policy.

Author Contributions: Conceptualisation, C.H.; methodology, validation and analysis, C.T.; policy implications, C.T. and C.H.; writing—original draft preparation, C.T.; writing—review and editing, C.T. and C.H. All authors have read and agreed to the published version of the manuscript.

Funding: This research was funded by the National Natural Science Foundation of China (Grant No. 71972127 and Grant No. 71874123).

Conflicts of Interest: The authors declare that they have no conflict of interest.

\section{References}

1. Van Dijk, J. The Network Society: Social Aspects of New Media; Sage Publications Ltd.: London, UK, 2006; pp. 19-20.

2. Castells, M. The Information Age: Economy, Society, and Culture Volume I: The Rise of the Network Society; John Wiley \& Sons: Chichester, UK, 2010; pp. 60-61.

3. Castells, M. Informationalism, networks, and the network society: A theoretical blueprint. In The Network Society: Across-Cultural Perspective; Castells, M., Ed.; Edward Elgar: Northampton, MA, USA, 2004; pp. 3-45.

4. Castells, M.; Cardoso, G. The Network Society: From Knowledge to Policy; Johns Hopkins Center for Transatlantic Relations: Washington, DC, USA, 2005; pp. 4-16.

5. Zheng, Z.Y.; He, M.S. Analysis of the Concept of "Network Society". Sociol. Study 2004, 1, 13-21.

6. He, Z. Basic Features of Network Society and Its Public Governance Strategy. Gov. Res. J. Gansu Adm. Inst. 2014, 3, 56-66.

7. O'Hare, M. Not on My Block You Don't-Facility Siting and the Strategic Importance of Compensation. Public Policy 1977, 4, 407-458.

8. Walsh, E.; Smith, R.W.C. Backyards, NIMBYs, and Incinerator Sitings: Implications for Social Movement Theory. Soc. Probl. 1993, 1, 25-38. [CrossRef]

9. Lober, D.J.; Green, D.P. NIMBY or NIABY: A Logit Model of Opposition to Solid-waste-disposal Facility Siting. J. Environ. Manag. 1994, 1, 33-50. [CrossRef]

10. Gibson, T.A. NIMBY and the civic good. City Community 2005, 4, 381-401. [CrossRef]

11. Greenberg, C. Liberal NIMBY: American jews and civil rights. J. Urban Hist. 2012, 3, 452-466. [CrossRef]

12. Dear, M. Understanding and overcoming the NIMBY syndrome. J. Am. Plan. Assoc. 1992, 3, 288-302. [CrossRef]

13. Sakai, T. Fair waste pricing: An axiomatic analysis to the NIMBY problem. Econ. Theory 2012, 2, 499-521. [CrossRef]

14. Hou, G.H.; Wang, Y.D. Why NIMBY crisis evolutes-An integrated attribution model. J. Public Manag. 2014, 3, 80-92.

15. Zhang, L.; Tong, X. Social generative mechanism for “NIMBY" actions. J. Jiangsu Adm. Inst. 2013, 1, 64-70.

16. Zhu, Z.W.; Wang, Q.; Wu, J. The occurrence and evolution logic of nimby conflict: Based on the empirical investigation of the local people of a coal mine facilities. Nanjing Soc. Sci. 2017, 3, 81-89.

17. Tang, H.H. NIMBY effect: The compensation mechanisms and citizen participation in public works projects. China Public Adm. 2011, 7, 111-114. 
18. Yang, Q.; Zhu, Y.X.; Liu, X.X.; Fu, L.M.; Guo, Q.Q. Bayesian-based NIMBY crisis transformation path discovery for municipal solid waste incineration in China. Sustainability 2019, 11, 2364. [CrossRef]

19. Zhang, L.; Tong, X. The policy dilemmas in the "NIMBY" conflict management and solutions. China Public Adm. 2014, 4, 109-113.

20. Wong, S.H.; Ye, X.Y. An analysis on the government response to internet political participation for decision-making: Taking protest-against px in ningbo as an example. J. Public Manag. 2013, 4, $26-36$.

21. Zhou, Y.Y.; Zhou, P.F.; Yu, H.S. The analysis on the site selection decision for NIMBY facilities. Zhejiang Soc. Sci. 2016, 6, 89-94.

22. Corin, S.E.; McNeill, A.; Atapattu, A. Democracy and risk-based decision-making: The next step in public involvement. J. Risk Res. 2012, 8, 1021-1026. [CrossRef]

23. Zeng, Z.M.; Li, L. The theoretical construction of public reason decision-making model. J. Public Manag. 2014,2 , 1-12.

24. Huang, Z.W. "Semi-public decision-making model”-governments' strategy on responding to NIMBY conflict. J. Hunan Univ. 2015, 4, 132-136.

25. Irvin, R.A.; Stansbury, J. Citizen participation in decision-making: Is it worth the effort? Public Adm. Rev. 2004, 1, 55-65. [CrossRef]

26. Willrich, M. The energy-environment conflict: Siting electric power facilities. Va. Law Rev. 1972, 2, 257-336. [CrossRef]

27. Simon, H.A. Bounded rationality. In Utility and Probability; Eatwell, J., Milgate, M., Newman, P., Eds.; The Macmillan Press Limited: London, UK, 1990; pp. 15-18.

28. Jin, S.; Du, J.G.; Sheng, Z.H. Evolutionary game analysis of regional environmental protection programme. Syst. Eng.-Theory Pract. 2015, 12, 3107-3118.

29. Smith, J.M.; Price, G.R. The logic of animal conflict. Nature 1973, 5427, 15-18. [CrossRef]

30. Taylor, P.D.; Jonker, L.B. Evolutionarily stable strategies and game dynamics. Math. Biosci. 1978, 1, 145-156. [CrossRef]

31. Gintis, H. The Bounds of Reason: Game Theory and the Unification of the Behavioral Sciences; Princeton University Press: Princeton, NJ, USA, 2009; pp. 1-2.

32. Jörgen, W. Evolutionary Game Theory; The MIT Press: Cambridge, MA, USA, 1995; pp. 9-13.

33. Li, Y.L.; Ding, Y. Research on social trust repair of public crisis governance under network public opinion-Based on an empirical analysis of evolutionary game of animal epidemic public crisis. J. Public Manag. 2017, 4, 91-101.

34. Xia, Z.Q.; Luo, S.C. Divergence and Evolution: Game Analysis of NIMBY Conflict. Expand. Horiz. 2015, 5, 67-73.

35. Yan, Y.G.; Yao, Q.X.; Liu, R.; Li, H. Evolutionary Game Analysis of Public Participation Behavior in the Planning of Pollution NIMBY Facilities. Urban Dev. Stud. 2017, 24, 91-97.

36. Qian, K.; Huang, Z.Q.; Liu, X.F. Environmental Compensation of NIMBY Facility Based on Evolutionary Game Theory. Syst. Eng. 2017, 3, 88-94.

37. Zhou, Y.A.; Feng, X.Y.; Zhao, J.Y. Local governments' competition and reconstruction of market order. Soc. Sci. China 2004, 1, $56-65$.

38. Jin, T.J. From administering administrative divisions to regional public administration: A game analysis of evolution in the pattern of governance by the government. Soc. Sci. China 2008, 4, 48-62. [CrossRef]

39. Oates, W.E. Searching for leviathan: An empirical study. Am. Econ. Rev. 1985, 4, 748-757.

40. Smelser, N.J. Theory of Collective Behavior; Free Press: New York, NY, USA, 1962; pp. 15-17.

41. Zhang, K.Z.; Xiang, Y.Q. Construction of Policy Issues in Cyberspace. Soc. Sci. China 2015, 2, $123-138$. 